\title{
A MUDANÇA DO REGIME CAMBIAL E O SEU IMPACTO NA BALANÇA COMERCIAL BRASILEIRA $^{1}$
}

\author{
Léo da Rocha Ferreira ${ }^{2}$ \\ Carlos Alberto Gonçalves da Silva ${ }^{3}$ \\ Paulo Fernando Cidade de Araújo ${ }^{4}$
}

\begin{abstract}
Resumo - O objetivo geral deste artigo é avaliar o impacto da mudança do regime cambial, de janeiro de 1999, e as transformações decorrentes experimentadas pelo setor agrícola brasileiro. Especificamente, objetivou analisar o desempenho da balança comercial brasileira em relação ao produto interno bruto ou produto agropecuário, à renda mundial e à taxa de câmbio real no período 1980-2006 (até o $1^{\circ}$.trimestre). As principais conclusões mostram que a política de bandas cambiais, no primeiro qüinquiênio do Plano Real, exerceu influência negativa nas exportações e favoreceu as importações. A partir da liberação cambial de 1999, embora as estimativas não sejam estatisticamente significativas, as indicações de reversão deste cenário são positivas.
\end{abstract}

Palavras-chave: Política cambial, balança comercial, agricultura brasileira.

\section{Introdução}

A administração da política econômica de um país exige constante acompanhamento e avaliação da sua balança comercial. Assim, tornase necessário avaliar os fatores que determinam seu desempenho.

A liberação cambial faz parte da ampliação do movimento internacional de capitais, fato que evidencia o sucesso da política cambial anterior à desindexação da economia ao câmbio. Nos países industrializados, a

\footnotetext{
1 Os autores agradecem à valiosa colaboração de Joana Sévilla e Gabriela Pinho, alunas do Curso de Graduação em Ciências Econômicas da UERJ. Também agradecem os comentários e sugestões valiosas recebidas de dois pareceristas anônimos desta revista, isentando-os, contudo, de quaisquer erros e omissões remanescentes. 2 Professor Titular da Universidade do Estado do Rio de Janeiro (UERJ). E-mail: leorocha@uerj.br

3 Professor Visitante da Universidade do Estado do Rio de Janeiro (UERJ). E-mail: gon.silva@ soft2.com.br

4 Professor do Centro Universitário Geraldo Di Biasi (UGB), ex-Professor Visitante da Universidade do Estado do Rio de Janeiro (UERJ) e Professor Titular aposentado da ESALQ / USP. E-mail: pfcaraujo@ gmail.com
} 
flexibilização do câmbio ganhou maior impulso no início dos anos setenta, com abertura e integração financeira dos mercados. Nos anos noventa, esse processo acelerou ainda mais, alcançando os países emergentes. Muitos $^{5}$ vêem essa integração como inevitável, considerando a ampliação do comércio, o papel das multinacionais e os avanços tecnológicos da informática e das comunicações. Com o câmbio flexível, a liberdade do movimento de capitais diminui o espaço para políticas irresponsáveis.

O papel do setor agrícola neste processo é considerável, como motor do crescimento da economia brasileira. A agricultura representa, atualmente, cerca de $10 \%$ do PIB total. No entanto, quando se considera o complexo agroindustrial, no qual também são incluídos os fornecedores de bens (insumos modernos e bens de capital) e serviços para a agricultura, os processadores e transformadores de matérias-primas (na agroindústria) e, por fim, os distribuidores envolvidos no fluxo e no marketing de produtos até o consumidor final, a contribuição do chamado agribusiness para a geração de riquezas do país torna-se muito maior, ultrapassando $30 \%$ do PIB $^{6}$. Soma-se a isso o fato de a agricultura brasileira possuir vantagens comparativas irrefutáveis, que melhor situam o Brasil na economia mundial.

A Figura 1 mostra a evolução da balança comercial brasileira no período de 1980 a 2004. Não houve grandes variações no saldo da balança comercial, que foi positivo de 1981 a 1995; contudo, no período de 1995 a 2000, o saldo foi negativo. Já partir de 2000, refletindo a mudança no regime cambial, o saldo da balança comercial apresentou incremento substancial.

\footnotetext{
Ver, por exemplo, Valls Pereira (1998), Ferreira (2004) e outros autores na coletânea organizada por Brandão e Valls Pereira (1998).

6 Veja Ferreira (1994).
} 


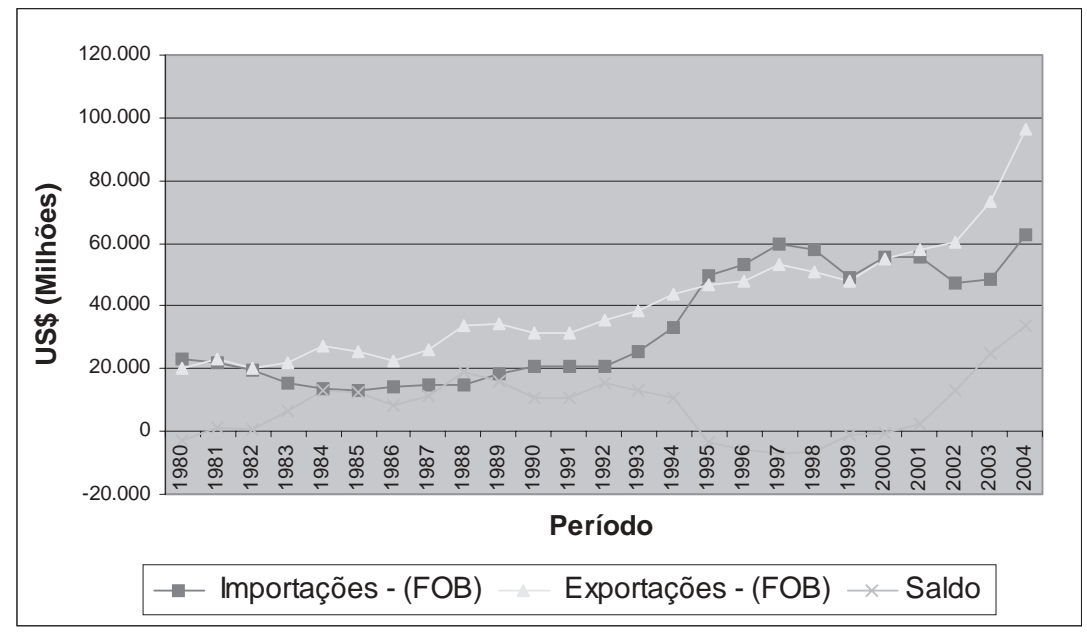

Figura 1-Evolução das exportações (FOB), importações (FOB) e saldo da balança comercial do Brasil

Nos anos 80, a crise da dívida externa brasileira determinou uma política de estímulo às exportações, enquanto as importações foram mantidas em baixos patamares. Taxas de câmbio reais e revigoramento da estrutura de proteção comercial constituíram instrumentos essenciais, o que pode ser observado pela oscilação da taxa de câmbio efetiva real na Figura 2, em um mesmo patamar até 1987/1988. 


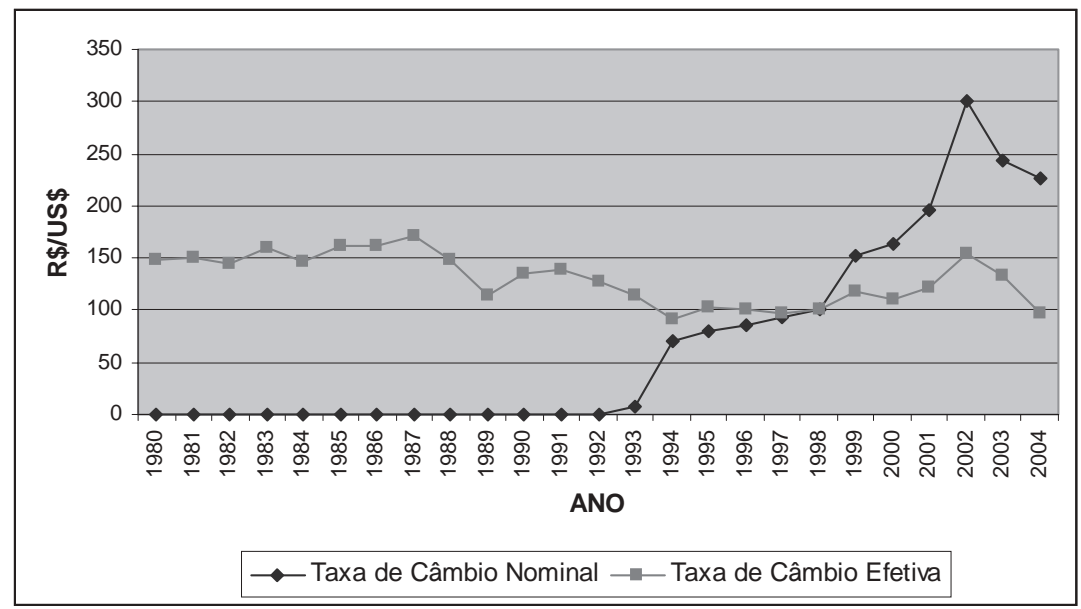

Figura 2 - Evolução do índice da taxa de câmbio nominal e efetiva real.

Já na primeira metade dos anos 90, ocorreu forte ascensão das importações, a partir da liberalização comercial e financeira, para permitir a entrada dos capitais que se dirigiam à América Latina. Apesar do crescimento médio anual de 8,2\% nas exportações, durante o período 1990/1995, os significativos saldos comerciais positivos reduziram-se a partir do ano de 1992, até mudarem de sinal a partir do último trimestre de 1994. A partir de 1989, a taxa de câmbio efetiva real voltou a subir, alcançando um pico em meados de 1991, e voltou a cair até o final de 1994, quando então se estabilizou até 1998.

A introdução do câmbio flutuante em 1999 acarretou novo incremento na taxa de câmbio efetiva real, que passou a flutuar abaixo da taxa de câmbio nominal (Figura 1). Após a crise cambial de 1999, quando as pressões externas provocaram reduções consideráveis nas reservas cambiais brasileiras, implantou-se o regime de câmbio flutuante. De acordo com Ferreira (2005), embora não houvesse plena liberdade de operação no mercado cambial brasileiro, em razão de diversas intervenções das autoridades monetárias, a flutuação do real passou a servir como válvula para descarregar as pressões internacionais, sem haver necessidade de mobilizar grandes quantidades de reservas ou de restringir à remessa de 
divisas ao exterior. Contudo, é sempre bom lembrar que o regime de câmbio flutuante foi implementado em ambiente de fundamentos pouco sólidos, dada a permanência de déficits nas contas públicas e nas transações correntes, o que gerava crescente desconfiança por parte dos investidores.

Nos países onde vigora o regime cambial flutuante e as cotações são determinadas pela relação entre procura e oferta, pode ocorrer, às vezes, um movimento de depreciação da moeda local, geralmente devido ao desequilíbrio no balanço de pagamentos. O equilíbrio pode ser restabelecido mediante, por exemplo, investimento direto de empresas estrangeiras no país e captação de empréstimos no exterior. Contudo, qualquer evento que possa trazer dúvidas acerca do balanço de pagamentos do país acaba interferindo no mercado de câmbio, criando um efeito circular. ${ }^{7}$

O objetivo geral deste artigo é examinar o impacto da mudança do regime cambial, implantado em janeiro de 1999, e possíveis efeitos econômicos de longo prazo, em particular os efeitos correspondentes nas transformações experimentadas pelo setor agrícola brasileiro. Especificamente, seu objetivo é avaliar o desempenho da balança comercial brasileira em relação à taxa de câmbio real, à renda mundial e ao produto interno bruto ou produto agropecuário.

Dentre as principais perguntas a serem esclarecidas neste trabalho incluem-se: i) Quais as relações existentes entre as variáveis explanatórias (produto interno bruto ou agropecuário, renda mundial e taxa de câmbio real) e a variável dependente, saldo da balança comercial brasileira? ii) As mudanças na política cambial, durante o Plano Real (regime de bandas até janeiro de 1999 e de câmbio livre até o presente), teriam exercido alterações importantes no desempenho da balança comercial? e iii) Quais os coeficientes de elasticidade relativos às variáveis explanatórias principais?

${ }^{7}$ Ver Ferreira (2005), op. cit. 


\section{Breve revisão da literatura}

O importante papel desempenhado pela taxa de câmbio nas transações comerciais de um país justifica, plenamente, o estudo dos fatores que a determinam. Na literatura econômica brasileira e internacional, os estudos empíricos a esse respeito são, certamente, numerosos. Alguns trabalhos recentes são comentados a seguir.

A taxa de câmbio de equilíbrio, na ausência de distorções na política comercial, foi estimada no período 1960/1983, para o Brasil, por Brandão e Carvalho (1989), que observaram que, para os objetivos da pesquisa, os dados existentes eram deficientes. Contudo, após submeterem os valores estimados da taxa de câmbio de equilíbrio a um teste de confiabilidade, concluíram que as estimativas eram um indicador da taxa de câmbio que equilibraria a conta corrente na ausência de todas as distorções existentes na política comercial.

Duas teorias de determinação da taxa de câmbio; a Paridade de Compra da Moeda (PPC) e a Paridade da Taxa de Juros (PTJ), foram testadas e avaliadas por Rossi (1991), que utilizou a técnica de co-integração. Quando empregados dados do período 1980/1988, os resultados para a PPC não foram conclusivos, enquanto a teoria da PTJ não pôde ser rejeitada. O estudo também concluiu, no período considerado, não haver relação estável, de longo prazo, entre as taxas de câmbio dos mercados oficiais e paralelos.

Os impactos da política de minidesvalorização no saldo da balança comercial foram estudados por Zini Jr. (1993), a partir de modelos com variantes, na metodologia de cálculo da taxa de câmbio e na especificação das variáveis explicativas. O estudo utilizou procedimentos convencionais de estimação, sem, contudo, analisar as condições de estacionariedade das séries temporais, o que gerou um conjunto de regressões espúrias. Apesar da má especificação dos modelos, suas conclusões apontam forte correlação entre saldo comercial e taxa de câmbio real. 
O processo de liberalização cambial no Brasil foi examinado por Gonçalves (1996), no contexto da globalização financeira, com ênfase na questão da conversibilidade da conta capital, ou seja, no sentido mais restrito da conversibilidade associada ao movimento internacional de capitais. Concluiu, de modo geral, que a globalização financeira e a liberalização cambial têm contribuído para aumentar a vulnerabilidade externa da economia brasileira, razão por que recomendou uma política de maior controle no movimento de capitais.

Em novo estudo, Rossi (1996) desenvolveu um modelo monetário de determinação da taxa de câmbio, ao utilizar a técnica de co-integração a partir do procedimento de Johansen, com dados mensais de janeiro de 1980 a junho de 1994. Suas conclusões não rejeitam a hipótese de paridade do poder de compra. Para este autor, este resultado não deixou de ser surpreendente, pois esta teoria se aplica a um regime de taxas de câmbio flexíveis, o que não era o caso do país na época. Segundo o próprio autor, "...os resultados sugerem que, apesar das freqüentes intervenções oficiais neste mercado, o que tem, às vezes, levado a certas sobrevalorizações da moeda doméstica, as autoridades econômicas têm, em geral, buscado manter a paridade do poder de compra da moeda."

Ao reconhecer os elevados custos da produção de tecnologia e da deficiência na capacitação tecnológica da indústria nacional, em geral, e no setor de bens de capital, em particular, Resende (1997) desenvolveu e estimou funções de demanda de importações totais e de bens de capital para o Brasil. A partir da suposição de que uma variável de disponibilidade cambial deva ser contemplada como argumento dessas funções, verificou a necessidade de reestruturação do setor produtivo industrial brasileiro, para que ocorram transformações na estrutura produtiva em direção aos setores intensivos em capital e tecnologia.

A experiência do Brasil e da Argentina na administração de seus regimes antidumping, anti-subsídios e de salvaguardas foi analisada por Piani (1998), que sugeriu maior moderação na aplicação de medidas antidumping externamente, bem como sua abolição e substituição por políticas de regulação da competição de países membros. 
Por meio de um modelo de análise diferencial-estrutural, Kume e Piani (1998) avaliaram o impacto dos fluxos de comércio, no âmbito do MERCOSUL, na produção brasileira, no período 1990/1995. O estudo quantificou os impactos das exportações e importações para e do MERCOSUL no valor da produção.

Moreira, Fiorencio e Lima (1998), por meio de modelos auto-regressivos vetoriais estruturais, realizaram estudo com o objetivo de analisar os impactos das políticas monetárias e cambial na taxa de desemprego e no nível de preços no período posterior ao Plano Real. Os resultados sugerem que houve mudança de regime econômico, com o Plano Real, e que os preços e o desemprego foram sensíveis aos efeitos da política monetária.

O impacto da redução do custo Brasil na defasagem cambial foi avaliado por Pessôa (1998). O principal resultado obtido foi que os ganhos de produtividade no setor de bens comercializáveis reduzem o atraso cambial; no setor de bens domésticos, elevam o atraso cambial; e em ambos os setores, o resultado dependerá da resposta da demanda. Se a elasticidaderenda da demanda do bem doméstico for maior do que a do bem comercializável, o atraso cambial será reduzido, caso contrário, elevarse-á.

As relações entre taxas de câmbio reais, elasticidades-renda de importações e exportações e saldo comercial na economia brasileira, no período 1981/1995, foram estudadas por Holland, Canuto e Xavier (1998). Pelo estudo, concluiu-se que, conhecida a meta de desvalorização cambial em relação à taxa de câmbio que anularia o déficit comercial, a entrada de capital necessária seria tanto maior quanto forem as elasticidadesrenda e elasticidades-preço das importações, assim como a referida elasticidade-câmbio da competitividade.

No estudo de Rocha e Moreira (1998), usou-se um processo de difusão geral, de Wiener, com descontinuidades discretas e pouco freqüentes, com um processo de Poisson, para analisar a credibilidade e a vulnerabilidade da política cambial vigente. Os resultados indicam que a taxa de câmbio flutuava dentro de uma minibanda e que se desvalorizava 
de forma errática, segundo tendência estável. Ademais, concluiu-se que a política cambial teve mais credibilidade antes da crise asiática em 1998, pela possibilidade de utilização da mesma técnica de mensuração de credibilidade, aplicada a mercados de opção cambial de moeda em outros países que adotaram bandas cambiais no mesmo período. Nesse sentido, pode-se inferir como o mercado avalia a credibilidade cambial de diferentes países sujeitos ao mesmo evento externo.

Schwtsman (1999), ao estudar a crise cambial dos anos 90 com base na literatura referente às crises de balanço de pagamentos, apontou um desequilíbrio fundamental na taxa de câmbio real. Concluiu-se que o nível da taxa de câmbio real não era consistente com a condição de solvência no longo prazo do balanço de pagamentos, mesmo a níveis reduzidos de atividade econômica. Em razão das dificuldades de se manter a política cambial atual, recomendou a flutuação cambial, em face da possibilidade de condução de política monetária e de redução, mais à frente, do componente financeiro do déficit público.

A pesquisa de Nonnemberg e Mendonça (1999) objetivou estudar a ocorrência de desvio de comércio decorrente da criação do MERCOSUL, especialmente a possibilidade de perdas acentuadas da produção da agricultura brasileira, principalmente nas culturas típicas da região Sul. Concluíram que a criação de comércio superou, amplamente, o desvio de comércio, tanto individualmente quanto para o conjunto dos seis produtos analisados (trigo, algodão, arroz, gado bovino, leite e milho).

A validação da hipótese de paridade do poder de compra, para o Brasil, foi avaliada em estudo de co-integração realizado por Holland e Valls Pereira (1999), no período 1974/1997. A pesquisa enfatizou as dúvidas existentes acerca da medida empírica da taxa de câmbio real mais adequada a ser utilizada. Por fim, reconheceu que as diversas medidas empíricas de câmbio real, muitas vezes, modificam, de modo significativo, a avaliação do tamanho do desalinhamento cambial e o seu eventual efeito sobre o saldo comercial. 
Os resultados de trabalho realizado por Sachsida e Teixeira (1999), no qual se utilizou um tratamento econométrico baseado em análise de cointegração, indicam que as medidas institucionais são mais eficientes do que a desvalorização cambial para corrigir desvios na conta corrente do balanço de pagamentos.

Em pesquisa recente feita por Pereira e Carvalho (2000), que utilizaram dados da matriz insumo-produto de 1995 e analisaram o impacto da depreciação da taxa de câmbio nos custos dos principais setores da economia brasileira, concluiu-se que a mudança do câmbio promove elevação direta dos custos nos setores que dependem de insumos importados.

A análise dos efeitos nas economias dos países membros do MERCOSUL, que objetivou mostrar as diferenças existentes entre comércio regional específico e entre este e o de outros países, usando índices de comércio intra-setorial, orientação de comércio e intensidade comercial, foi realizada por Guimarães (2000). Os resultados evidenciam a criação de vantagens comparativas dinâmicas na região, bem como modificações no comportamento dos setores industriais intensivos em capital e tecnologias favoráveis à adoção de estratégias multilaterais de comércio exterior.

Goldfajn e Olivares (2001) citaram um levantamento feito por Hausmann e outros (1999), que mostra que a habilidade da taxa de câmbio de flutuar livremente está intimamente relacionada com o nível de desenvolvimento de um país. Os resultados indicam que quanto mais desenvolvido for o país, mais volátil será a taxa de câmbio, tanto em relação ao nível das reservas internacionais quanto à taxa de juros.

A partir de um survey com questionários enviados a 4.494 firmas exportadoras brasileiras, as principais barreiras não-tarifárias (BNT) aplicadas pelos países do MERCOSUL às exportações brasileiras foram estudadas por Kume, Anderson e Oliveira Jr. (2001). Foram identificadas 16 barreiras não-tarifárias, divididas em visíveis e invisíveis. As invisíveis mais citadas foram exigência de etiqueta, trâmites aduaneiros excessivos, 
inspeção prévia e requisitos de inspeção e testes. Pela pesquisa, concluiuse que os principais entraves às exportações brasileiras podem ser corrigidos por meio de medidas que visem à harmonização nas exigências contidas nas etiquetas e nas certificações sanitárias e fitossanitárias, fim da aplicação dos direitos antidumping e adoção de procedimento aduaneiro único entre os países do MERCOSUL.

Recente e abrangente coletânea de pesquisas organizada por Baumman (2001) reúne informações e análises sobre formação e trajetória do MERCOSUL. O conjunto de trabalhos apresentados objetivou aprofundar as discussões sobre temas variados, todos eles voltados para uma efetiva integração regional.

Na literatura, há considerável número de técnicas para solução de modelos econométricos que envolvem efeitos retardados e distribuídos ao longo do tempo ${ }^{8}$. Tendo em vista os efeitos distributivos das variáveis explicativas dos modelos econométricos, Kmenta (1974) sugeriu a utilização de um modelo de defasagem-V invertido, no qual se obtêm os pesos w, em:

$\mathrm{Y}_{\mathrm{t}}=\alpha+\beta\left(\mathrm{w}_{0} \mathrm{X}_{\mathrm{t}}+\mathrm{w}_{1} \mathrm{X}_{\mathrm{t}-1}+\ldots+\mathrm{w}_{\mathrm{m}} \mathrm{X}_{\mathrm{t}-\mathrm{m}}\right)+\varepsilon_{\mathrm{t}}$

de um polinômio de certo grau. Esses modelos são conhecidos, na literatura, como modelos de defasagem polinomial. Em decorrência, um polinômio do grau $\boldsymbol{p}$ tem pesos $\mathrm{w}_{-1}, \mathrm{w}_{0}, \mathrm{w}_{1}, \ldots, \mathrm{w}_{\mathrm{m}}, \mathrm{w}_{\mathrm{m}+1}$, de modo que $\mathrm{w}_{-1}=\begin{array}{lll}0 & \mathrm{e} & \mathrm{w}_{\mathrm{m}+1}=0 .\end{array}$

O impacto das variáveis que influenciam a balança comercial costuma ser medido pelas elasticidades de curto prazo e longo prazo. De modo geral, admite-se que a desvalorização cambial poderá melhorar a balança comercial, quando as elasticidades-preço de demanda forem positivas:

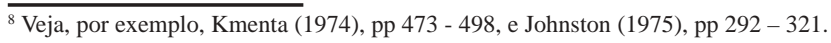




$$
\left.\frac{\varepsilon_{x}\left(\eta_{x-1}\right)}{\varepsilon_{x+\eta_{x}}}+\frac{\eta_{m\left(1+\varepsilon_{m}\right)}}{\boldsymbol{E}_{m}+\eta_{m}}\right\rangle,
$$

em que $\boldsymbol{\varepsilon}_{\mathrm{x}}$ é elasticidade-preço da oferta de exportações; $\boldsymbol{\eta}_{\mathbf{x}}$, elasticidadepreço da demanda de exportações; $\boldsymbol{\varepsilon}_{\mathbf{m}}$, elasticidade-preço da oferta de importações; $\boldsymbol{\eta}_{\mathbf{m}}$, elasticidade-preço da demanda de importações

Segundo Krueger (1983), diversos fatores podem afetar a balança comercial de determinado país. Contudo, três deles devem, necessariamente, constar de especificação econométrica que tenha por objetivo explicar o seu comportamento, quais sejam, a taxa de câmbio real e os níveis de renda doméstica e mundial.

Ao utilizarem dados dos anos de 1970 e início dos anos de 1980, Braga e Rossi (1987) estimaram uma equação para a balança comercial brasileira, tendo como variáveis explicativas o produto industrial, a renda mundial e a taxa de câmbio real. O interesse desse estudo foi examinar como o efeito dessas variáveis foi distribuído ao longo do tempo.

A taxa de câmbio real, também conhecida como termos de troca, é o preço relativo dos bens de dois países, calculada a partir da taxa de câmbio nominal e dos níveis de preços vigentes nos dois países considerados, medidos nas suas respectivas moedas. ${ }^{9}$

Desse modo, a taxa de câmbio real E é igual ao produto da taxa de câmbio nominal e pela razão dos níveis de preços $\mathbf{P} * / \mathbf{P}$, em que $\mathbf{P}^{*}$ é preço dos bens no outro país e $\mathbf{P}$, preço dos bens no mercado interno.

Logo,

$\mathbf{E}=\mathbf{e}\left(\mathbf{P}^{*} / \mathbf{P}\right)$.

Conseqüentemente, uma taxa de câmbio real maior do que a taxa de câmbio nominal significa que os bens e serviços estrangeiros são relativamente mais caros quando comparados aos preços dos bens e serviços domésticos.

\footnotetext{
9 Veja discussão detalhada sobre a taxa de câmbio real em Helmers (1995).
} 
Caso essa taxa seja menor, os bens e serviços estrangeiros estarão relativamente mais baratos em relação aos bens nacionais.

\section{Material e método}

À luz da teoria econômica, são esperadas relações positivas entre os pares de variáveis especificados no modelo econométrico. Para os objetivos deste estudo, é adotada, inicialmente, a seguinte especificação econométrica para a balança comercial ${ }^{10}$ :

$\mathrm{Y}=f\left(\mathrm{X}_{1}, \mathrm{X}_{2}, \mathrm{X}_{3}\right)$,

em que $Y$ é saldo trimestral da balança comercial, em US\$; $\mathrm{X}_{1}$ taxa de câmbio real efetiva trimestral (em numero índice, $2000=100$ ); $X_{2}$, renda mundial trimestral (em número-índice, 2000=100); e $\mathrm{X}_{3}$, PIB agropecuário trimestral (em numero índice, 2000=100).

Para elaboração da variável, foi adotada, para a renda mundial, a seguinte definição:

$X_{2}=$ a soma trimestral das exportações mundiais.

A taxa de câmbio efetiva real objetivou captar o efeito-preço e, neste sentido, incorporar possíveis distorções introduzidas pela política comercial (subsídios às exportações e restrições às importações). Como anteriormente sugerido, a taxa de cambio real é definida por

$\mathrm{X}_{1}=\alpha \mathrm{P} * \mathrm{P}$

em que

$\alpha$ é taxa de câmbio nominal (real/dólar norte americano); $\mathrm{P}^{*}$, índice de preços dos Estados Unidos, segundo a OCDE; e P, índice de preços por atacado do Brasil (IPA-OG da FGV).

${ }^{10}$ Forma reduzida de um modelo que, na sua forma estrutural, inclui uma equação para as exportações e outra para as importações. 
Tendo em vista as diferentes políticas cambiais adotadas ao longo do período 1980-2004, tornou-se necessária a introdução de mais duas variáveis explicativas no presente modelo:

$\mathrm{X}_{4}=$ Dummy referente à implementação do Plano Real em agosto de 1994;

$\mathrm{X}_{5}=$ Dummy referente à mudança para câmbio flutuante em janeiro de 1999.

Ademais, como as decisões são tomadas com base em dados anteriores, é preferível adotar um modelo de defasagem, em que

$$
\begin{aligned}
& \mathrm{Y}_{\mathrm{t}}=f\left(\mathrm{Y}_{\mathrm{t}-1}\right) \\
& \mathrm{X}_{1(\mathrm{t})}=f\left(\mathrm{X}_{1(\mathrm{t}-1)}\right) \\
& \mathrm{X}_{2(\mathrm{t})}=f\left(\mathrm{X}_{2(\mathrm{t}-1)}\right) \\
& \mathrm{X}_{3(\mathrm{t})}=f\left(\mathrm{X}_{3(\mathrm{t}-1)}\right)
\end{aligned}
$$

Com base na inclusão e especificação das variáveis citadas, obtém-se, finalmente, o seguinte modelo:

$$
\mathrm{Y}_{(\mathrm{t}-1)}=\mathrm{b}_{0}+\mathrm{b}_{1} * \mathrm{X}_{1(\mathrm{t}-1)}+\mathrm{b}_{2} * \mathrm{X}_{2(\mathrm{t}-1)}+\mathrm{b}_{3} * \mathrm{X}_{3(\mathrm{t}-1)}+\mathrm{b}_{4} * \mathrm{X}_{4(\mathrm{t})}+\mathrm{b}_{5} * \mathrm{X}_{5(\mathrm{t})}
$$

A análise empírica utilizou dados secundários do Banco Central, do IBGE e do IPEA, disponíveis na Internet. No período em análise, os dados trimestrais somam $\underline{\mathbf{1 0 5}}$ observações.

Os seguintes testes foram realizados com o propósito de selecionar as variáveis mais importantes e examinar a estacionariedade das séries temporais. ${ }^{11}$ Inicialmente, realizou-se o teste $t$, de Student, para os regressores $\left(b_{i}\right)$ do modelo. Para isso, foram propostas as seguintes hipóteses:

11 Para maiores detalhes sobre os testes econométricos, consultar Gujarati (1998) e Kmenta (1974). 
$\mathrm{H}_{\mathrm{o}}$ : O coeficiente $\mathrm{b}_{\mathrm{i}}=0$ para $(\mathrm{i}=1,2,3,4,5,6) ; \log$, a variável $\mathrm{X}_{\mathrm{i}}$ não é significativa no modelo.

$\mathrm{H}_{\mathrm{a}}$ : O coeficiente $\mathrm{b}_{\mathrm{i}} \neq 0$ para $(i=1,2,3,4,5,6)$, ou seja, a variável $\mathrm{X}_{\mathrm{i}}$ é explicativa no modelo.

O nível de significância estabelecido no teste $t$ é de $5 \%$.

Em se tratando de séries de tempo, fez-se necessário verificar a estacionariedade de cada série, utilizando o correlograma amostral e a função de autocorrelação (FAC). Esta função, na defasagem $k$, é definida por

$$
\rho_{k}=\frac{\sum(Y-\bar{Y})\left(Y_{t+k}-\bar{Y}\right) / n}{\sum\left(Y_{t}-\bar{Y}\right) / n},
$$

em que n é número de observações trimestrais; $\underset{Y}{-}$, média da variável dependente; $k$, número de defasagens.

Se $\rho_{k}=0$, a série será estacionária; se $\rho_{k} \neq 0$, não-estacionária.

Em regressões com séries de tempo, é necessário verificar se as variáveis são estacionárias, para evitar o problema da chamada regressão espúria ou duvidosa. A regressão espúria ocorre quando se tenta ajustar modelos com variáveis não-estacionárias que as direcionam, no mesmo sentido, ao longo do tempo e apresentam tendência comum.

Assim, para testar a hipótese se a série é estacionária ou não, utiliza-se, neste trabalho, o teste de raiz unitária ou de Dickey-Fuller, estimando-se numa regressão do tipo $\Delta \mathrm{Y}_{\mathrm{t}}=\gamma \mathrm{Y}_{\mathrm{t}-1}+\mathrm{e}_{\mathrm{t}}$. Portanto, a hipótese pode ser formulada como segue: 
$\mathrm{H}_{0}: \gamma=0$ - presença de raiz unitária ou série não-estacionária.

Ha; $\gamma \neq 0$ - ausência de raiz unitária ou série estacionária.

Com vistas em verificar a existência ou não de autocorrelação serial, utiliza-se o teste de Godfrey, que consiste, inicialmente, em ajustar a seguinte equação:

$Y_{t}=\beta_{0}+\beta_{1} X_{t}+\beta_{2} e_{t-1}+\beta_{3} e_{t-2}+\ldots+\beta_{k} e_{t-m}+v_{t}$.

Este teste pode ser aplicado, sem restrições, a modelos que incluem variáveis dependentes defasadas.

No caso de se constatar a existência de autocorrelação, aplica-se a correção de Cochrane-Orcutt. A partir das variáveis transformadas, em defasagem de ordem $k$, serão feitos também os testes de estacionariedade e de autocorrelação serial, conforme descritos anteriormente.

\section{Análise dos resultados}

Inicialmente, o modelo econométrico, ajustado pelo Método dos Mínimos Quadrados Ordinários (MQO), foi o seguinte:

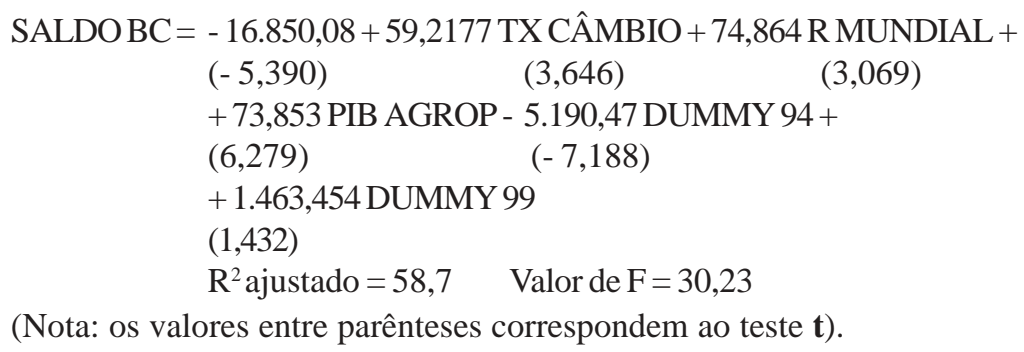

(Nota: os valores entre parênteses correspondem ao teste $\mathbf{t}$ ).

Como esperado, os sinais dos coeficientes de regressão das variáveis câmbio, renda mundial e produto bruto da agropecuária são positivos, o 
que sinaliza a validade das hipóteses inicialmente propostas. O modelo apresenta, para os coeficientes das variáveis principais, níveis de significância superiores a 5 \% (valor crítico da estatística $t$ ), com exceção do coeficiente da variável dummy 99, estatisticamente significativo a $10 \%$. O coeficiente de determinação múltiplo ajustado $\left(\mathrm{R}^{2}\right)$ indica que as variáveis independentes podem explicar $58,7 \%$ das variações na balança comercial brasileira.

O teste de autocorrelação, de Godfrey, indica que a regressão estimada possui autocorrelação nos resíduos. Assim, aplicou-se o método de Cochrane-Orcutt para corrigir o problema. Isto significa que o modelo transformado e estimado pelo método dos Mínimos Quadrados Ordinários passou a ser:

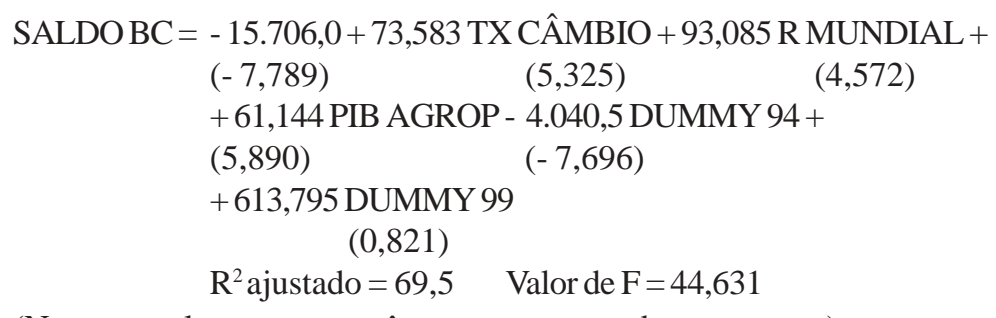

(Nota: os valores entre parênteses correspondem ao teste $t$ ).

A 5\% de significância, quase todos os coeficientes das variáveis explicativas são significativos, exceto, novamente, o que corresponde à variável dummy 99. O coeficiente de determinação múltiplo ajustado $\left(\mathrm{R}^{2}\right)$ indica que as variáveis independentes podem explicar 69,5\% das variações na balança comercial brasileira.

Tais resultados sugerem razoável nível de estabilidade do modelo inicial para o modelo transformado. Além disso, os valores dos coeficientes apresentam magnitude semelhante.

A Tabela 1 apresenta os resultados dos testes Dickey-Fuller, pelo modelo transformado. Pode-se observar que as estatísticas $t$, calculadas para os modelos 1, 2 e 4, são superiores ao valor crítico, a 5\% de significância. 
Logo, pode-se rejeitar a hipótese nula, ou seja, presença de raiz unitária.

Quanto ao Modelo 3, a estatística $t$ calculada é inferior ao valor crítico, de 5\%. Portanto, aceita-se a hipótese nula de raiz unitária, rejeitando-se, em conseqüência, a estacionaridade da série.

Tabela 1 - Resultados do Teste DF - Dickey - Fuller

\begin{tabular}{lllcc}
\hline Modelo & Variável & Equação de Teste & $\begin{array}{c}\text { Estatística }-t \\
(\mathrm{DF})\end{array}$ & $\begin{array}{c}\text { Valor Crítico } \\
(5 \%)\end{array}$ \\
\hline 1 & Balança Comercial & Constante & $-9,310$ & $-1,944$ \\
\hline 2 & Taxa de Câmbio & Constante & $-2,380$ & $-1,944$ \\
\hline 3 & Renda Mundial & Constante & $-1,601$ & $-1,944$ \\
\hline 4 & PIB Agropecuário & Constante & $-4,314$ & $-1,944$ \\
\hline
\end{tabular}

Fonte: Resultados da pesquisa.

Vale realçar que os resultados do teste DFA (acumulado) foram pouco diferentes dos obtidos no teste DF (simples), constantes da Tabela 1.

$\mathrm{Na}$ Tabela 2 aparecem as estimativas dos coeficientes de elasticidade das variáveis taxa de câmbio real, renda mundial e PIB agropecuário. Todos são positivos e maiores que um (coeficientes relativamente elásticos). Esses resultados sugerem que o saldo da balança comercial brasileira seja bastante sensível às variações percentuais nas variáveis independentes do modelo. Além disso, em ordem de importância econômica para a balança comercial, destacam-se a renda mundial e a taxa real de câmbio.

Tabela 2 - Elasticidades estimadas a partir do modelo

\begin{tabular}{ll}
\hline Discriminação & \multicolumn{1}{c}{ Elasticidade } \\
\hline Elasticidade - Taxa de Câmbio & 3,10 \\
\hline Elasticidade - Renda Mundial & 4,21 \\
\hline Elasticidade - PIB Agropecuário & 2,72 \\
\hline
\end{tabular}

Fonte: Resultados da pesquisa. 
Para avaliar os possíveis efeitos das mudanças na política cambial - regime de bandas no início do Plano Real e câmbio flutuante a partir de 1999 - as estimativas do modelo transformado sugerem que o regime de câmbio fixo (representado pela dummy 94) teria exercido efeito negativo sobre o saldo da balança comercial, sendo tal efeito estatisticamente significativo, em nível superior a 5\%. Em contrapartida, a mudança de regime para o câmbio flutuante sugere, como esperado, efeito positivo sobre o saldo. Após a transformação do modelo original, no entanto, o coeficiente estimado para a variável dummy 99 não foi estatisticamente significativo.

Do ponto de vista empírico, o excelente desempenho do saldo da balança comercial, a partir de 2001, suporta, parcialmente, a hipótese proposta nesta pesquisa.

\section{Conclusão}

A taxa de câmbio, a renda mundial e o PIB agropecuário são variáveis relevantes para explicar o desempenho da balança comercial brasileira. Objetivamente, o modelo transformado pelo método de Coochrane-Orcutt representa o comportamento, de longo prazo, do saldo de transações comerciais do país com o resto do mundo.

Considerando que as estimativas feitas a partir do modelo inicial e, a seguir, do modelo transformado revelaram-se positivas em vários aspectos, verifica-se que há aceitação dos resultados deste último modelo, uma vez que ele minimiza o problema de autocorrelação serial. Entre os pontos positivos deste modelo, estão os seguintes: i) Coerência com a teoria e com a evidência empírica; ii) Estabilidade e magnitude dos coeficientes de regressão; e iii) Elevados níveis de significância das estimadas elasticidades, na seguinte ordem: renda mundial, taxa de câmbio real e PIB agropecuário. É interessante realçar que, em pesquisa de Gonçalves Júnior (2005), a renda mundial foi também a variável mais importante para explicar o saldo da balança comercial do complexo agroindustrial brasileiro, o que revela elasticidade ligeiramente superior à unidade. 


\section{Referências}

BAUMMANN, R. (org.). MERCOSUL - avanços e desafios da integração. Brasília, IPEA/CEPAL, 2001, 479p.

BRAGA, H. C. \& ROSSI, J. W. "A dinâmica da balança comercial no Brasil, 1970-84", Revista Brasileira de Economia, 41(1): 237-48, abril/ junho de 1987.

BRANDÃO, A. S. P. \& VALLS PEREIRA, L. (orgs.). MERCOSUL - perspectivas de integração. Rio de Janeiro: Editora da FGV, $3^{\mathrm{a}}$ edição, 1998.

\& CARVALHO, J. L. "Uma estimativa da taxa e câmbio de equilíbrio de livre comércio para o Brasil, 1960-83". Revista Brasileira de Economia, 43(1): 3-18, janeiro / março de 1989.

DICKEY, D. A., FULLER, W. A. "Distribution of the estimates for autoregressive time series with a unit root". Journal of the American Statistical Association, v. 74, p.427-431, June 1979.

FERREIRA, L. R. "Taxa de câmbio social e abertura comercial", Revista Economia Aplicada, 9(4): 645-662, outubro/dezembro de 2005.

. Taxa de câmbio social no Brasil: MERCOSUL e abertura comercial. Rio de Janeiro: Editora Letra Capital, 2004.

. "Pesquisa agrícola: uma agenda para o tempo do complexo agroindustrial". In: IPEA. O Brasil no fim do século: desafios e propostas para a ação governamental, Rio de Janeiro, IPEA, Setembro de 1994, pp. 279-85.

GOLDFAJN, I. \& OLIVARES, G. "Taxas de câmbio flexíveis podem ainda funcionar em economias financeiramente abertas". Textos para Discussão do G-24, nº 8, UNCTAD, janeiro de 2001. 
GONÇALVES, R. "Globalização financeira, liberalização cambial e vulnerabilidade externa da economia brasileira”. In: BAUMANN, R. (org.), O Brasil e a economia global. Rio de Janeiro, Editora Campus, 1996.

GONÇALVES JÚNIOR, O. Determinantes da balança comercial do complexo agro-industrial brasileiro: 1970 - 2002. Dissertação (Mestrado), Universidade do Estado do Rio de Janeiro (UERJ), Rio de Janeiro, 2005.

GUIMARÃES, E. P. Componente tecnológico comparativo das exportações ao MERCOSUL e ao resto do mundo. Rio de Janeiro, IPEA, Texto para Discussão No 765, outubro de 2000, 63p.

GUJARATI, D. Econometria básica. São Paulo: Makron Books, 1998.

HAUSMAN, R.; GAVIN, M.; PÁGES-SERRA, C.; \& STEIN, E. H. Financial turmoil and the choice of exchange rate regime, Working Paper 400, Washington, Banco Inter-Americano de Desenvolvimento, disponível via Internet na web page: $\underline{w w w . i a d b . o r g / o c e / 33 . c f m ? c o d e=1, ~} 1999$.

HELMERS, F. Leslie C. H. "The real exchange rate". In: DORNBUSCH, R. \& HELMERS, F.L.C.H. (eds.) The open economy - tools for policymakers in developing countries. Nova Iorque: Oxford University Press, 1995.

HOLlAND, M.; CANUTO, O. \& XAVIER, C. "Taxas de câmbio, elasticidades-renda e saldo comercial na economia brasileira, Revista Brasileira de Economia, 52(2): 323-334, abril / junho de 1998".

. \& VALLS PEREIRA, P. L. "A taxa de câmbio real a paridade do poder de compra no Brasil". Revista Brasileira de Economia, 53(3): 259-285, julho / setembro de 1999.

JOHNSTON, J. Econometric methods. Nova Iorque, McGraw-Hill Book Company, $2^{\text {a }}$ edição, 1975. 
KMENTA, J. Elements of econometrics. Nova Iorque: The Macmillan Company, 1974.

KUME, H. \& PIANI, G. Efeitos regionais do MERCOSUL: uma análise diferencial-estrutural para o período 1990/98. Rio de Janeiro, IPEA, Texto para Discussão Nº 585, agosto de 1998, 32p.

; ANDERSON, P. \& OLIVEIRA JR, M. Identificação

das barreiras ao comércio no MERCOSUL: a percepção das empresas exportadoras brasileiras. Rio de Janeiro, IPEA, Texto para Discussão No 789, maio de 2001, 43p.

KRUEGER, Anne D. Exchange rate determination. Cambridge: Cambridge University Press, 1983.

MOREIRA, A. R. B., FLORENCIO, A. \& LIMA, E. C. R. Os impactos das políticas monetária e cambial no Brasil Pós-Plano Real. Rio de Janeiro, IPEA, Texto para Discussão No 579, agosto de 1998, 25p.

NONNEMNDERG, M. J. B. \& MENDONÇA, M. J. C. Criação $\boldsymbol{e}$ desvio de comércio no MERCOSUL: o caso dos produtos agrícolas. Rio de Janeiro, IPEA, Texto para Discussão Nº 631, março de 1999, $17 \mathrm{p}$.

PEREIRA, T. R. \& CARVALHO, A. C. Desvalorização cambial e o seu impacto sobre os custos e preços industriais no Brasil - uma análise dos efeitos de encadeamento nos setores produtivos. Rio de Janeiro, IPEA, Texto para Discussão No 771, março de 2000, 26p.

PESSÔA, S. A. "O impacto da redução do custo Brasil sobre a defasagem cambial". Revista Brasileira de Economia, 52(2): 279-310, abril / junho de 1998.

PIANI, G. Medidas antidumping, anti-subsídios e de salvaguardas: experiência recente e perspectivas no MERCOSUL. Rio de 
Janeiro, Texto para Discussão $N^{0}$ 541, janeiro de 1998, 23p.

RESENDE, M. F. C. Disponibilidade cambial e especificação da função de demanda de importações. Rio de Janeiro, IPEA, Texto para Discussão Nº 506, agosto de 1997, 38p.

ROCHA, K. M. C. \& MOREIRA, A. R. B. Credibilidade da política cambial e as opções cambiais, Rio de Janeiro, IPEA, Texto para Discussão Nº 581, agosto de 1998.

ROSSI, J. W. "O modelo monetário de determinação da taxa de câmbio: testes empíricos para o Brasil". Pesquisa e Planejamento Econômico, 26(2): 155-182, agosto de 1996.

. "Determinação da taxa de câmbio: testes empíricos para o Brasil". Pesquisa e Planejamento Econômico, 21(2): 397-412, agosto de 1991.

SACHSIDA, A. \& TEIXEIRA, J. R. Impactos de desvalorizações cambiais sobre a conta corrente no Brasil. Brasília, IPEA, Texto para Discussão No 660, agosto de 1999, 24p.

SCHWARTSMAN, A. "A crise cambial e o ajuste fiscal". Revista de Economia Política, 19(1); 5-29, janeiro / março de 1999.

ZINI JR., A.A. A taxa de câmbio e a política cambial no Brasil. São Paulo, Edusp/BM\&F, 1993. 


\begin{abstract}
The purpose of this paper is to evaluate the impact of the change on the Brazilian exchange rate policy implemented in January 1999, and to analyze agricultural sector transformations. Specifically, the paper is an attempt to identify the economic relations of the aggregate performance of the Brazilian commercial trade balance and total GDP or agricultural GDP, world income, and real exchange rate as of in the 19802006 (up to first quarter) period. The main conclusion of the study is that the exchange rate policy bands of Plano Real exerted a negative effect on exports and favored imports. With the liberation of the Brazilian exchange rate, from 1999 on, the estimated relations appear to have a positive net effect on the commercial trade balance of the country. But the statistical results of the econometric model are not reliable.
\end{abstract}

Key words: Exchange Rate Policy, Commercial Trade Balance, Brazilian Agriculture. 
Léo da Rocha Ferreira, Carlos Alberto G. da Silva \& Paulo Fernando Cidade de Araújo

Apêndice 1 - Dados utilizados na pesquisa: variáveis principais

\begin{tabular}{crrrr}
\hline $\begin{array}{c}\text { Ano/ } \\
\text { Trimestre }\end{array}$ & $\begin{array}{c}\text { Saldo da Balança } \\
\text { Comercial }\left(\mathbf{Y}_{\mathbf{t}}\right)\end{array}$ & $\begin{array}{c}\text { Taxa de Câmbio } \\
\text { Real }\left(\mathbf{X}_{\mathbf{1}}\right)\end{array}$ & $\begin{array}{c}\text { Renda } \\
\text { Mundial }\left(\mathbf{X}_{\mathbf{2}}\right)\end{array}$ & $\begin{array}{c}\text { PIB } \\
\text { Agropecuário }\left(\mathbf{X}_{\mathbf{3}}\right)\end{array}$ \\
\hline $1980 \mathrm{~T} 1$ & $-1.368,79$ & 103,8660667 & 92,8195 & 67,37261852 \\
\hline $1980 \mathrm{~T} 2$ & $-670,602$ & 102,3000333 & 94,6882 & 96,65928223 \\
\hline $1980 \mathrm{~T} 3$ & $-836,186$ & 100,3553667 & 97,5299 & 62,05582632 \\
\hline $1980 \mathrm{~T} 4$ & 52,811 & 92,4077 & 98,2294 & 52,24634471 \\
\hline 1981 T1 & $-419,685$ & 88,59666667 & 98,4533 & 69,27780239 \\
\hline 1981 T2 & 108,904 & 84,36926667 & 96,0813 & 108,5511741 \\
\hline 1981 T3 & 532,012 & 83,04393333 & 93,5644 & 69,25121843 \\
\hline 1981 T4 & 981,224 & 86,37263333 & 96,0796 & 53,43376163 \\
\hline 1982 T1 & 48,848 & 81,9603 & 94,4616 & 71,24501551 \\
\hline 1982 T2 & 99,359 & 77,77973333 & 92,6191 & 100,1772264 \\
\hline 1982 T3 & 206,425 & 72,71586667 & 90,877 & 68,55117412 \\
\hline 1982 T4 & 425,441 & 77,12473333 & 89,8897 & 59,87594152 \\
\hline 1983 T1 & 721,548 & 86,89863333 & 89,7013 & 67,4523704 \\
\hline 1983 T2 & $2.069,13$ & 102,5396333 & 87,8499 & 102,241914 \\
\hline 1983 T3 & $2.062,19$ & 101,8152667 & 86,5386 & 73,28311918 \\
\hline 1983 T4 & $1.617,53$ & 105,4348333 & 86,9818 & 55,48958795 \\
\hline 1984 T1 & $2.381,17$ & 107,0412 & 87,6363 & 72,06025698 \\
\hline 1984 T2 & $3.596,10$ & 109,0899333 & 87,7521 & 105,0420913 \\
\hline 1984 T3 & $3.628,09$ & 108,2382 & 85,4124 & 71,21843155 \\
\hline 1984 T4 & $3.484,16$ & 107,2619333 & 83,7055 & 57,9973416 \\
\hline 1985 T1 & $1.902,75$ & 105,4110333 & 81,2626 & 76,88081524 \\
\hline 1985 T2 & $3.540,92$ & 115,719 & 83,1933 & 115,7022596 \\
\hline 1985 T3 & $3.626,65$ & 115,1794667 & 85,0205 & 80,87727071 \\
\hline 1985 T4 & $3.415,20$ & 113,3464 & 87,768 & 62,21533008 \\
\hline 1986 T1 & $2.460,45$ & 113,8103667 & 90,0462 & 73,58440408 \\
\hline 1986 T2 & $3.699,31$ & 116,485 & 89,7732 & 103,6863093 \\
\hline 1986 T3 & $2.484,05$ & 115,5852 & 91,4235 & 71,42224191 \\
\hline 1986 T4 & $-339,511$ & 111,027 & 93,1568 & 60,05316792 \\
\hline & & & &
\end{tabular}


REVISTA DE ECONOMIA E AGRONEGÓCIO, VOL.4, $N^{o} 2$

\begin{tabular}{|c|c|c|c|c|}
\hline $1987 \mathrm{~T} 1$ & 586,67 & 103,5466 & 97,2983 & 75,76428888 \\
\hline 1987 T2 & $2.892,06$ & 106,0600333 & 99,6695 & 122,0646876 \\
\hline $1987 \mathrm{~T} 3$ & $4.382,88$ & 115,6259667 & 99,6604 & 88,8435977 \\
\hline $1987 \mathrm{~T} 4$ & $3.311,48$ & 112,1007 & 104,166 & 68,29419584 \\
\hline $1988 \mathrm{~T} 1$ & $3.173,48$ & 109,4502 & 103,73 & 85,24590164 \\
\hline $1988 \mathrm{~T} 2$ & $5.471,50$ & 109,6347333 & 105,093 & 119,8670802 \\
\hline $1988 \mathrm{~T} 3$ & $5.969,59$ & 104,0996 & 102,83 & 84,6167479 \\
\hline $1988 \mathrm{~T} 4$ & $4.569,54$ & 105,8265 & 105,696 & 68,21444395 \\
\hline $1989 \mathrm{~T} 1$ & $4.180,17$ & 100,5238333 & 106,141 & 86,32698272 \\
\hline $1989 \mathrm{~T} 2$ & $4.803,63$ & 78,32026667 & 107,273 & 125,5117412 \\
\hline 1989 T3 & $4.136,12$ & 80,9046 & 104,72 & 85,32565352 \\
\hline $1989 \mathrm{~T} 4$ & $2.999,27$ & 75,66406667 & 106,734 & 70,98803722 \\
\hline $1990 \mathrm{~T} 1$ & $1.910,18$ & 64,6133 & 110,337 & 79,14931325 \\
\hline $1990 \mathrm{~T} 2$ & $4.034,20$ & 65,95846667 & 110,47 & 117,6517501 \\
\hline $1990 \mathrm{~T} 3$ & $3.261,40$ & 67,89933333 & 114,544 & 85,75985822 \\
\hline $1990 \mathrm{~T} 4$ & $1.546,61$ & 81,9075 & 119,903 & 71,89189189 \\
\hline $1991 \mathrm{~T} 1$ & $3.481,25$ & 83,54553333 & 116,308 & 78,01506424 \\
\hline $1991 \mathrm{~T} 2$ & $3.711,91$ & 78,2998 & 108,583 & 98,09481613 \\
\hline $1991 \mathrm{~T} 3$ & $1.821,50$ & 75,96226667 & 108,462 & 95,87062472 \\
\hline $1991 \mathrm{~T} 4$ & $1.565,31$ & 89,2022 & 112,406 & 87,32831192 \\
\hline $1992 \mathrm{~T} 1$ & $3.213,46$ & 91,91046667 & 111,946 & 87,4523704 \\
\hline $1992 \mathrm{~T} 2$ & $3.826,07$ & 91,00933333 & 112,495 & 102,738148 \\
\hline $1992 \mathrm{~T} 3$ & $4.259,73$ & 92,63806667 & 117,952 & 97,92645104 \\
\hline $1992 \mathrm{~T} 4$ & $3.939,63$ & 88,92156667 & 111,586 & 88,77270713 \\
\hline $1993 \mathrm{~T} 1$ & $3.980,89$ & 85,5355 & 107,893 & 82,26849801 \\
\hline $1993 \mathrm{~T} 2$ & $3.143,58$ & 87,3781 & 109,426 & 98,20115197 \\
\hline $1993 \mathrm{~T} 3$ & $3.042,08$ & 85,0676 & 107,235 & 104,8028356 \\
\hline $1993 \mathrm{~T} 4$ & $3.132,22$ & 84,918 & 106,432 & 91,31590607 \\
\hline $1994 \mathrm{~T} 1$ & $2.828,15$ & 82,6137 & 106,262 & 83,73061586 \\
\hline $1994 \mathrm{~T} 2$ & $3.949,27$ & 83,18933333 & 109,117 & 100,7620735 \\
\hline $1994 \mathrm{~T} 3$ & $4.251,02$ & 83,12306667 & 113,118 & 113,0350022 \\
\hline $1994 \mathrm{~T} 4$ & $-561,9714$ & 73,9776 & 114,654 & 99,60124058 \\
\hline $1995 \mathrm{~T} 1$ & $-2.287,17$ & 72,7586 & 118,539 & 84,7053611 \\
\hline
\end{tabular}


Léo da Rocha Ferreira, Carlos Alberto G. da Silva \& Paulo Fernando Cidade de Araújo

\begin{tabular}{|c|c|c|c|c|}
\hline $1995 \mathrm{~T} 1$ & $-2.287,17$ & 72,7586 & 118,539 & 84,7053611 \\
\hline 1995 T2 & $-1.938,61$ & 75,46466667 & 123,078 & 105,8484714 \\
\hline $1995 \mathrm{~T} 3$ & 577,363 & 73,8867 & 122,488 & 120,5937085 \\
\hline $1995 \mathrm{~T} 4$ & 182,803 & 72,5849 & 122,273 & 102,1621622 \\
\hline $1996 \mathrm{~T} 1$ & $-465,238$ & 71,07293333 & 120,874 & 89,9335401 \\
\hline $1996 \mathrm{~T} 2$ & 126,138 & 70,3044 & 118,917 & 112,255206 \\
\hline 1996 T3 & $-1.261,77$ & 70,6115 & 119,343 & 120,4519273 \\
\hline $1996 \mathrm{~T} 4$ & $-3.998,18$ & 71,66516667 & 118,481 & 103,5356668 \\
\hline $1997 \mathrm{~T} 1$ & $-831,972$ & 70,47363333 & 114,52 & 94,69206912 \\
\hline $1997 \mathrm{~T} 2$ & $-1.331,96$ & 70,41716667 & 112,225 & 112,8754984 \\
\hline 1997 T3 & $-1.685,90$ & 70,79243333 & 110,271 & 114,8072663 \\
\hline $1997 \mathrm{~T} 4$ & $-2.903,06$ & 72,01266667 & 110,29 & 100,2569783 \\
\hline $1998 \mathrm{~T} 1$ & $-1.837,79$ & 70,3672 & 105,764 & 90,25254763 \\
\hline $1998 \mathrm{~T} 2$ & 10,733 & 70,8897 & 105,429 & 124,6964998 \\
\hline $1998 \mathrm{~T} 3$ & $-1.775,49$ & 72,38986667 & 104,385 & 118,2809039 \\
\hline $1998 \mathrm{~T} 4$ & $-2.971,96$ & 75,38143333 & 106,74 & 94,771821 \\
\hline $1999 \mathrm{~T} 1$ & $-815,501$ & 106,7391 & 104,325 & 106,8498006 \\
\hline $1999 \mathrm{~T} 2$ & 199,682 & 100,3118667 & 103,771 & 130,5981391 \\
\hline $1999 \mathrm{~T} 3$ & $-150,121$ & 107,8547667 & 102,96 & 122,1533008 \\
\hline $1999 \mathrm{~T} 4$ & $-432,928$ & 109,3008 & 104,662 & 104,0496234 \\
\hline $2000 \mathrm{~T} 1$ & $-18,627$ & 99,52556667 & 101,718 & 116,6947275 \\
\hline $2000 \mathrm{~T} 2$ & 804,3917 & 99,91466667 & 100,533 & 136,1187417 \\
\hline $2000 \mathrm{~T} 3$ & $-109,575$ & 98,05966667 & 99,9725 & 120,7975188 \\
\hline $2000 \mathrm{~T} 4$ & $-1.373,94$ & 102,4963333 & 97,7767 & $\overline{100}$ \\
\hline $2001 \mathrm{~T} 1$ & $-678,454$ & 107,0255667 & 99,4272 & 122,711564 \\
\hline $2001 \mathrm{~T} 2$ & 611,493 & 117,4248 & 96,5321 & 141,5950377 \\
\hline $2001 \mathrm{~T} 3$ & $1.331,56$ & 127,4200333 & 96,1176 & 126,1320337 \\
\hline $2001 \mathrm{~T} 4$ & $1.385,86$ & 122,5280667 & 93,7952 & 110,4386354 \\
\hline $2002 \mathrm{~T} 1$ & $1.027,42$ & 105,1251667 & 92,8098 & 129,1891892 \\
\hline $2002 \mathrm{~T} 2$ & $1.558,49$ & 108,9441 & 95,6394 & 150,6247231 \\
\hline $2002 \mathrm{~T} 3$ & $5.266,26$ & 135,3521667 & 98,4262 & 134,8338502 \\
\hline $2002 \mathrm{~T} 4$ & $5.269,12$ & 151,9024333 & 101,101 & 113,9743022 \\
\hline
\end{tabular}


REVISTA DE ECONOMIA E AGRONEGÓCIO, VOL.4, $N^{o} 2$

\begin{tabular}{|c|c|c|c|c|}
\hline $2003 \mathrm{~T} 1$ & $3.804,75$ & 141,8416 & 103,549 & 142,8622065 \\
\hline $2003 \mathrm{~T} 2$ & $6.592,56$ & 121,5998667 & 105,553 & 161,6836509 \\
\hline $2003 \mathrm{~T} 3$ & $7.392,71$ & 120,7843333 & 105,375 & 131,0589278 \\
\hline $2003 \mathrm{~T} 4$ & $7.011,41$ & 124,8538667 & 112,383 & 119,4328755 \\
\hline $2004 \mathrm{~T} 1$ & $6.142,24$ & 129,5024333 & 116,555 & 152,0425343 \\
\hline $1991 \mathrm{~T} 4$ & $1.565,31$ & 89,2022 & 112,406 & 87,32831192 \\
\hline $1992 \mathrm{~T} 1$ & $3.213,46$ & 91,91046667 & 111,946 & 87,4523704 \\
\hline $1992 \mathrm{~T} 2$ & $3.826,07$ & 91,00933333 & 112,495 & 102,738148 \\
\hline $1992 \mathrm{~T} 3$ & $4.259,73$ & 92,63806667 & 117,952 & 97,92645104 \\
\hline $1992 \mathrm{~T} 4$ & $3.939,63$ & 88,92156667 & 111,586 & 88,77270713 \\
\hline $1993 \mathrm{~T} 1$ & $3.980,89$ & 85,5355 & 107,893 & 82,26849801 \\
\hline 1993 T2 & $3.143,58$ & 87,3781 & 109,426 & 98,20115197 \\
\hline $1993 \mathrm{~T} 3$ & $3.042,08$ & 85,0676 & 107,235 & 104,8028356 \\
\hline $1993 \mathrm{~T} 4$ & $3.132,22$ & 84,918 & 106,432 & 91,31590607 \\
\hline $1994 \mathrm{~T} 1$ & $2.828,15$ & 82,6137 & 106,262 & 83,73061586 \\
\hline $1994 \mathrm{~T} 2$ & $3.949,27$ & 83,18933333 & 109,117 & 100,7620735 \\
\hline $1994 \mathrm{~T} 3$ & $4.251,02$ & 83,12306667 & 113,118 & 113,0350022 \\
\hline $1994 \mathrm{~T} 4$ & $-561,9714$ & 73,9776 & 114,654 & 99,60124058 \\
\hline $1995 \mathrm{~T} 1$ & $-2.287,17$ & 72,7586 & 118,539 & 84,7053611 \\
\hline $1995 \mathrm{~T} 2$ & $-1.938,61$ & 75,46466667 & 123,078 & 105,8484714 \\
\hline $1995 \mathrm{~T} 3$ & 577,363 & 73,8867 & 122,488 & 120,5937085 \\
\hline $1995 \mathrm{~T} 4$ & 182,803 & 72,5849 & 122,273 & 102,1621622 \\
\hline $1996 \mathrm{~T} 1$ & $-465,238$ & 71,07293333 & 120,874 & 89,9335401 \\
\hline $1996 \mathrm{~T} 2$ & 126,138 & 70,3044 & 118,917 & 112,255206 \\
\hline $1996 \mathrm{~T} 3$ & $-1.261,77$ & 70,6115 & 119,343 & 120,4519273 \\
\hline $1996 \mathrm{~T} 4$ & $-3.998,18$ & 71,66516667 & 118,481 & 103,5356668 \\
\hline $1997 \mathrm{~T} 1$ & $-831,972$ & 70,47363333 & 114,52 & 94,69206912 \\
\hline $1997 \mathrm{~T} 2$ & $-1.331,96$ & 70,41716667 & 112,225 & 112,8754984 \\
\hline 1997 T3 & $-1.685,90$ & 70,79243333 & 110,271 & 114,8072663 \\
\hline $1997 \mathrm{~T} 4$ & $-2.903,06$ & 72,01266667 & 110,29 & 100,2569783 \\
\hline $1998 \mathrm{~T} 1$ & $-1.837,79$ & 70,3672 & 105,764 & 90,25254763 \\
\hline $1998 \mathrm{~T} 2$ & 10,733 & 70,8897 & 105,429 & 124,6964998 \\
\hline $1998 \mathrm{~T} 3$ & $-1.775,49$ & 72,38986667 & 104,385 & 118,2809039 \\
\hline $1998 \mathrm{~T} 4$ & $-2.971,96$ & 75,38143333 & 106,74 & 94,771821 \\
\hline
\end{tabular}


Léo da Rocha Ferreira, Carlos Alberto G. da Silva \& Paulo Fernando Cidade de Araújo

\begin{tabular}{|c|c|c|c|c|}
\hline $1999 \mathrm{~T} 1$ & $-815,501$ & 106,7391 & 104,325 & 106,8498006 \\
\hline $1999 \mathrm{~T} 2$ & 199,682 & 100,3118667 & 103,771 & 130,5981391 \\
\hline $1999 \mathrm{~T} 3$ & $-150,121$ & 107,8547667 & 102,96 & 122,1533008 \\
\hline $1999 \mathrm{~T} 4$ & $-432,928$ & 109,3008 & 104,662 & 104,0496234 \\
\hline $2000 \mathrm{~T} 1$ & $-18,627$ & 99,52556667 & 101,718 & 116,6947275 \\
\hline $2000 \mathrm{~T} 2$ & 804,3917 & 99,91466667 & 100,533 & 136,1187417 \\
\hline $2000 \mathrm{~T} 3$ & $-109,575$ & 98,05966667 & 99,9725 & 120,7975188 \\
\hline $2000 \mathrm{~T} 4$ & $-1.373,94$ & 102,4963333 & 97,7767 & 100 \\
\hline $2001 \mathrm{~T} 1$ & $-678,454$ & 107,0255667 & 99,4272 & 122,711564 \\
\hline $2001 \mathrm{~T} 2$ & 611,493 & 117,4248 & 96,5321 & 141,5950377 \\
\hline $2001 \mathrm{~T} 3$ & $1.331,56$ & 127,4200333 & 96,1176 & 126,1320337 \\
\hline $2001 \mathrm{~T} 4$ & $1.385,86$ & 122,5280667 & 93,7952 & 110,4386354 \\
\hline $2002 \mathrm{~T} 1$ & $1.027,42$ & 105,1251667 & 92,8098 & 129,1891892 \\
\hline $2002 \mathrm{~T} 2$ & $1.558,49$ & 108,9441 & 95,6394 & 150,6247231 \\
\hline $2002 \mathrm{~T} 3$ & $5.266,26$ & 135,3521667 & 98,4262 & 134,8338502 \\
\hline $2002 \mathrm{~T} 4$ & $5.269,12$ & 151,9024333 & 101,101 & 113,9743022 \\
\hline $2003 \mathrm{~T} 1$ & $3.804,75$ & 141,8416 & 103,549 & 142,8622065 \\
\hline $2003 \mathrm{~T} 2$ & $6.592,56$ & 121,5998667 & 105,553 & 161,6836509 \\
\hline $2003 \mathrm{~T} 3$ & $7.392,71$ & 120,7843333 & 105,375 & 131,0589278 \\
\hline $2003 \mathrm{~T} 4$ & $7.011,41$ & 124,8538667 & 112,383 & 119,4328755 \\
\hline $2004 \mathrm{~T} 1$ & $6.142,24$ & 129,5024333 & 116,555 & 152,0425343 \\
\hline $2004 \mathrm{~T} 2$ & $8.862,27$ & 126,9805 & 127,03 & 163,80 \\
\hline $2004 \mathrm{~T} 3$ & $10.065,67$ & 124,8549 & 122,057 & 163,96 \\
\hline $2004 \mathrm{~T} 4$ & $8.587,85$ & 121,07045 & 121,250 & 165,65 \\
\hline $2005 \mathrm{~T} 1$ & $8.304,51$ & 116,6119 & 116,793 & 167,25 \\
\hline $2005 \mathrm{~T} 2$ & $11.353,98$ & 106,4641 & 106,653 & 168,05 \\
\hline $2005 \mathrm{~T} 3$ & $12.981,65$ & 101,9203 & 101,437 & 163,02 \\
\hline $2005 \mathrm{~T} 4$ & $12.107,95$ & 96,7043 & 96,847 & 163,69 \\
\hline 2006T1 & $9.340,96$ & 95,2490 & 95,393 & 165,62 \\
\hline
\end{tabular}

Fonte: Banco Central, IBGE e IPEA. 
REVISTA DE ECONOMIA E AGRONEGÓCIO, VOL.4, $N^{\circ} 2$ 